\title{
Carbon Capture and Storage and the UNFCCC: Recommendations to Address Trans-Boundary Issues
}

\author{
Viviane Romeiro $^{1,2 *}$, Virginia Parente ${ }^{1,2}$ \\ ${ }^{1}$ Eletrotechnical and Energy Institute (IEE), University of Sao Paulo (USP), São Paulo, Brazil; ${ }^{2}$ Research Center of Carbon Emission \\ Policy and Regulation (NUPPREC), São Paulo, Brazil. \\ Email: *viviromeiro@usp.br, vparente@iee.usp.br
}

Received October $31^{\text {st }}, 2012$; revised December $1^{\text {st }}, 2012$; accepted December $9^{\text {th }}, 2012$

\begin{abstract}
This paper is mainly focused on the eligibility of trans-boundary Carbon Dioxide Capture and Storage (CCS) as a Clean Development Mechanism (CDM) project activity and it aims to explore a broad range of CCS trans-boundary issues whereby the United Nations Framework Convention on Climate Change (UNFCCC) and national governments could take into consideration. Much work is still to be done by the CCS community (including the Institute) to ensure that the implementation of CCS under the CDM is both environmentally effective and commercially attractive. The recommendations focus on technical issues, with the aim of helping Parties evaluate a robust strategy for CCS as part of international negotiations and establish CCS best practice criteria for governments and the international process, thereby enhancing transparency and ensuring that CCS deployment is safe and effective. When considering CDM projects activities with a trans-boundary component, it is recommend that the rules of the main international treaties related to CCS be considered by the UNFCCC, especially the London Protocol guidelines for risk assessment and management and the 2006 IPCC Guidelines. Additionally, national governments should apply the rules and guidelines as delineated under the relevant existing international treaties and CCS national regulations.
\end{abstract}

Keywords: Carbon Capture and Storage; Clean Development Mechanism; Transboundary CCS

\section{Introduction}

In December of 2011, the $17^{\text {th }}$ Conference of the Parties (COP-17) serving as the $7^{\text {th }}$ Meeting of the Parties to the Kyoto Protocol (CMP 07) has adopted the modalities and procedures for carbon dioxide capture and storage in geological formations as clean development mechanism project activities [1]. It has requested the Subsidiary Body for Scientific and Technological Advice to consider, at its eighth session:

a) The eligibility of carbon dioxide capture and storage project activities which involve the transport of carbon dioxide from one country to another or which involve geological storage sites that are located in more than one country;

b) The establishment of a global reserve of certified emission reduction units for carbon dioxide capture and storage project activities, in addition to the reserve referred to in paragraph 21(b) of the annex to this decision.

UNFCCC CDM options for trans-boundary CCS include a) to allow projects with a trans-boundary compo-

${ }^{*}$ Corresponding author. nent, and require joint governance and collaboration between DNAs b) to only allow projects without a transboundary component $[1]$.

Parties have been discussing various scenarios for trans-boundary movements of $\mathrm{CO}_{2}$, as well as the legality of such movements. Due to additional legal implication for trans-boundary CCS projects under CDM, some of them have previously expressed that it would be more appropriate to restrict these projects without a transboundary component, until more understanding has been reached. In a first phase, CCS should be eligible as a CDM project only when there is a very low probability of leakage and when long-term liability is feasible to be determined. By doing that, countries would have a period of "learning by doing", in order to minimize any environmental and economic risks related to cross-borders CCS projects [2].

Although Parties tended towards not allowing, at least at first, trans-boundary projects in the CDM, as they pose significant cross-border and regulatory challenges, one suggestion was made that trans-boundary issues could be handled as and when required, rather than attempting to address all the issues in modalities and procedures ex 
ante. The major concerns are mostly related (but not limited) to [2]:

- lack of an international CCS regulation, once national regulations are not yet set up to induce the establishment of an international framework;

- potential infringement of international law, since the relevant international treaties were not designed to accommodate CCS;

- uncertainty on the permanence of ocean storage;

- cross-border disagreements;

- long-term liability provisions;

- difficulties on GHG reporting.

However, others argue that trans-boundary projects do not add any extra challenges related to carbon dioxide storage in common reservoirs. It does, conversely, imply on identifying the responsible host country, which does require a very robust liability implication between the countries [3]. It was also mentioned that there are few current legal impediments in international law to the trans-boundary movement of $\mathrm{CO}_{2}$, and that such movements are generally allowable where they have been mutually agreed by all Parties involved.

Most of CCS projects would have project boundaries that fit well within the national borders of the host country [4], which means that, in practice, only few projects would have a trans-boundary component. However, it should be considered that some regions may have considerable $\mathrm{CO}_{2}$ emissions but limited storage capacity, (or conversely, large storage capacity and limited $\mathrm{CO}_{2}$ emission). In such cases, shared projects could play a key role to foster CCS.

There are currently many international, regional and local legal frameworks somewhat relevant to CCS activities and many definitions and prohibitions within these frameworks could be adequately broad to encompass and regulate various $\mathrm{CO}_{2}$ capture and geological storage activities. Although these actions allow CCS under international treaties, CCS projects that have spatial project boundaries that span national borders will require coordination and regulatory approval from both host governments.

The section is not meant to judge the adequacy of various regulatory approaches or be a comprehensive study of various jurisdictions' CCS-relevant regulations. It simply strives to compare CCS-specific regulations and regulatory proposals to each other to convey what are the main issues related and how they could be used in a possible CCS under CDM procedures that allow transboundary activities.

\section{International Treaties}

There exist a number of global and regional environmental treaties, notably those on climate change and the law of the sea and marine environment, which could be interpreted as relevant to the permissibility of $\mathrm{CO}_{2}$ storage, particularly offshore geological storage. Various international conventions could have implications for storage of $\mathrm{CO}_{2}$, the most significant being the UN Law of the Sea Convention, the London Convention, the Convention on Environmental Impact Assessment in a Transboundary Context (Espoo Convention) and OSPAR.

International law becomes particularly important in cases where the physical project boundary crosses national borders, enters international waters, or enters national waters that are governed by international treaties. Recent years have seen parties to a number of international marine treaties work to amend those treaties so that CCS projects are allowed under defined circumstances. Besides the UNFCCC and the Kyoto Protocol, the main international treaties for consideration in the context of geological $\mathrm{CO}_{2}$ storage are shown in Table 1.

This section summarizes the international law that has somewhat implications for CCS as a legitimate mechanism for $\mathrm{CO}_{2}$ disposal and presents some implications for trans-boundary CCS projects.

\subsection{London Convention}

The Convention on the Prevention of Marine Pollution by Dumping of Wastes and Other Matter 1972 (London Convention) [5] is the first international agreement to provide protection to the marine environment from the deliberate disposal at sea of wastes. Currently, 87 States are Parties to this Convention [6].

\section{Implications for CCS}

$\mathrm{CO}_{2}$ is not referred to in the Convention as a substance that cannot be dumped (Annex I) or that requires a special permit for dumping (Annex II). So, $\mathrm{CO}_{2}$ is not prohibited from being dumped and will require permitting under Annex III. The UCL Carbon Capture Legal Programme [7] sets that whether $\mathrm{CO}_{2}$ is in fact industrial waste (Annex I) or falls under other substances (Annexes II and III), it may still fall outside the need for permitting under the Convention, since the classification of dumping has two exceptions that could be relevant to CCS. There is, however, no international consensus as to whether $\mathrm{CO}_{2}$ storage may constitute placement, within the terms of the Convention.

The Convention is a framework for risk assessment and management and it includes guidelines for management as well as site selection, EIA, and monitoring. A new approach to waste management at sea was developed in the form of the 1996 Protocol to the Convention on the Prevention of Marine Pollution by Dumping of Wastes and Other Matter 1972 (London Protocol), which will be further discussed in the Section 2.6 of this report. 
Table 1. Main international treaties for consideration in the context of geological $\mathrm{CO}_{2}$ storage.

\begin{tabular}{cccc}
\hline Treaty & Adoption & Entry into Force & Number of Parties \\
\hline London Convention & 1972 & 1975 & 87 \\
UNCLOS & 1982 & 1994 & 145 \\
Basel Convention & 1989 & 1992 & 176 \\
Espoo Convention & 1991 & 1997 & 45 \\
OSPAR & 1992 & 1998 & 15 \\
London Protocol & 1996 & No & 41 \\
\hline
\end{tabular}

Source: IPCC, 2005. Adapted and updated by the authors.

\subsection{UNCLOS}

The United Nations Convention on the Law of the Sea was created in 1982 and it entered into force in 1994. The Convention was established to provide an overarching international agreement regulating the various uses of the world's oceans and seas. Its scope covers the use of resources, shipping, marine research, the exploitation of the exclusive economic zone and continental shelf, and the prevention and avoidance of marine pollution.

\section{Implications for CCS}

The Convention does not imply in any prohibition to CCS activities, but its requirements may somewhat impact where activities are considered to represent pollution. There is no decisive view if CCS would be considered as a pollutant within the scope of UNCLOS. The London Convention of 1972 and the later Protocol of 1996 contain global rules and standards with regard to dumping and marine pollution.

Although UNCLOS does not mention CCS, there are some provisions regarding the protection of the marine environment that could impact CCS projects, especially if the gas is considered to constitute pollution. It is uncertain, however, if CCS would be considered as a pollutant, which could be elucidated through amendment to state the implication for the technology [7]. Nations who aim to implement CCS under CDM with a trans-boundary component should follow the broad legislation of both UNCLOS and the London Convention, if they are Contracting Parties.

\subsection{The Basel Convention}

The Basel Convention on the Control of Trans-boundary Movements of Hazardous Wastes and their Disposal was created in 1989 and it came into force in 1992. The email of the Basel Convention is to assure a Environmentally Sound Management (ESM), which means the protection of human health and the environment by minimizing hazardous waste production whenever possible. ESM means addressing the issue through an "integrated lifecycle approach", which involves strong controls from the generation of a hazardous waste to its storage, transport, treatment, reuse, recycling, recovery and final disposal [8].

The Convention sets a framework to control transboundary movements of hazardous wastes across international frontiers, especially developing countries and highlights, in its Preamble, that States should take necessary measures to ensure that the management of hazardous wastes and other wastes.

\section{Implications for CCS}

The Basel Convention was conceived on the principle that an appropriate management of trans-boundary movement of wastes could encourage environmentally sound management among the parties in order to reduce the volume of waste. There is no indication, however, if $\mathrm{CO}_{2}$ would be considered a hazardous waste under the convention, except when it presents impurities during its capture process. Accordingly to [9], the Basel Convention does not appear to directly impose any restriction on the transportation of $\mathrm{CO}_{2}$.

\subsection{Espoo Convention}

The United Nations Economic Commission for Europe (UNECE) Convention on Environmental Impact Assessment in a Trans-boundary Context, was created in 1991 and came into force in 1997 . With 45 parties that have ratified this convention, it aims to prevent, reduce and control significant adverse trans-boundary environmental impact from proposed activities [10]. The Convention obliges states to provide an Environmental Impact Assessment (EIA) for all activities listed in Appendix I which are expected to provoke relevant trans-boundary impacts in another state, but it does not refer to CCS.

\section{Implications for CCS}

Appendix I includes oil refineries, coal gasification plants, offshore hydrocarbon production, etc, but do not mention any activity related to CCS or requires an EIA for $\mathrm{CO}_{2}$ transportation. However, the Espoo Convention may be relevant with a possible extension of its scope in order to include CCS activities. An amendment to Annex I would be a reasonable choice in respect of the recent 
amendment of the EU EIA Directive, which now includes $\mathrm{CO}_{2}$ pipeline infrastructures within its scope. The Convention seems also likely to be applied to CCS projects that might have a trans-boundary impact to non-EU Members [7].

\subsection{OSPAR}

The OSPAR Convention is the current legal instrument guiding international cooperation on the protection of the marine environment of the North-East Atlantic. Work under the Convention is managed by the OSPAR Commission, made up of representatives of the Governments of 15 Contracting Parties and the European Commission, representing the European Union. It started in 1972 with the Oslo Convention against dumping. These two conventions were unified, up-dated and extended by the 1992 OSPAR Convention. The OSPAR Convention entered into force on 25 March 1998.

\section{Implications for CCS}

In 2002, the OSPAR Convention has address CCS, when it has commissioned a report to decide how CCS fits into the OSPAR framework. The report concluded that shipbased disposal of carbon dioxide is prohibited. However, carbon dioxide disposal from land based sources, offshore activities, and for scientific study are permitted with authorization. The report also concluded that carbon dioxide injection into sub-seabed geological structures is allowed for offshore Enhanced Oil Recovery (EOR) activities.

OSPAR was amended in 2007 to allow CCS, and guidelines for risk assessment and management were adopted. The Convention provides a strict frame for preventing ocean pollution and as a result, it could imply in barriers for CCS activities. However, because many countries are signatories of both OSPAR and the London Convention and Protocol, it more likely that the OSPAR Convention will adopt language explicitly allowing carbon dioxide sub-seabed storage in the interest of legal cohesiveness.

\subsection{London Protocol}

Protocol to the Convention on the Prevention of Marine Pollution by Dumping of Wastes and Other Matter 1972 (London Protocol) was created in 1996 as a new approach to waste management at [11]. It prohibits ocean disposal of any material not specified in the Protocol and it sets out a general prohibition on the export of wastes or other matter to other countries for dumping or incineration at sea.

The Protocol [11] entered into force in 2006, after its ratification by 26 countries ( 15 of which had to be Contracting Parties to the original Convention. Currently there are 41 Parties in this Protocol [12]. The Protocol adopts a more stringent legal framework for preventing ocean waste disposal than its predecessor, the 1972 London Convention on the Prevention of Marine Pollution by Dumping of Wastes and Other Matter (the London Convention). In effect, the two instruments will continue to apply in parallel until such time as more Parties ratify the Protocol.

\section{Implications for CCS}

The London Protocol requests that all the countries willing to deploy trans-boundary CCS projects should establish an agreement with their respective responsibilities. The Contracting Parties to the Protocol (under the International Maritime Organization (IMO) adopted an amendment that came into force in 2007 and allows carbon dioxide storage in sub-seabed formations [12].

Accordingly to the amendment, the $\mathrm{CO}_{2}$ streams may be considered for dumping, as follows:

- disposal is into a sub-seabed geological formation;

- they consist overwhelmingly of carbon dioxide and no wastes or other matter are added for the purpose of disposing of those wastes or other matter.

Article 6 of the Protocol was amended in 2009 in order to allow exporting $\mathrm{CO}_{2}$ for CCS purposes [13], with the condition that all the protection standards are entirely addressed. Additionally, Parties adopted a work plan in 2010, with timelines to review the $2007 \mathrm{CO}_{2}$ Sequestration Guidelines ("Specific Guidelines for Assessment of Carbon Dioxide Streams for Disposal into Sub-seabed Geological Formations"). This work should enable the use of the expanded Guidelines on a voluntary basis, and consequently encouraging Parties to accept the amendment and bring the amendment into force [14].

\section{CCS Guidelines}

\subsection{IEA}

The International Energy Agency (IEA) CCS Model Regulatory Framework discusses regulatory issues that need to be addressed in order to demonstrate the technical, safety and environmental viability of industrial scale CCS projects [15]. The agency has identified three key regulatory actions for CCS, and among them, the international legal issue was highlighted, including development of an international monitoring and verification protocol for $\mathrm{CO}_{2}$ storage, and allowance of trans-boundary $\mathrm{CO}_{2}$ transfer under the London Protocol by 2012.

If the project boundary is defined to extend across different jurisdictions, all jurisdictions may need to approve participation in the particular project. The decision on whether or not a project's boundary should include the whole reservoir may need to vary by the type of CCS CDM project as well as by site-specific factors, which include [16]: 
- the exploration permit applications and authorizations;

- monitoring, inspections, closure and post-closure requirements;

- long-term responsibility for the storage site and any associated liabilities.

\subsection{IPCC}

The Special Report on Carbon Dioxide Capture and Storage from 2005 [9] provides information for policymakers, scientists and engineers in the field of climate change and reduction of $\mathrm{CO}_{2}$ emissions. It describes sources, capture, transport, and storage of $\mathrm{CO}_{2}$, and it also discusses issues related to projects with a transboundary component. According to its chapter 5, all the States can exercise their sovereignty in their territories and could therefore engage in activities such as the storage of $\mathrm{CO}_{2}$ (both geological and ocean) in those areas under their jurisdiction.

However, if storage has a trans-boundary impact, States have the responsibility to ensure that activities within their jurisdiction or control do not cause damage to the environment of other States or of areas beyond the limits of national jurisdiction. When interpreting the treaties for the purposes of determining the permissibility of $\mathrm{CO}_{2}$ storage, particularly offshore geological storage, it is important to bear in mind that the treaties were not drafted to facilitate geological storage but to prohibit marine dumping. There has been limited experience with CCS to date, but it is expected that experience will increase over the next few years. Therefore, it would be good practice to compare monitoring methods and possible leakage scenarios between comparable sites internationally. International cooperation will also be advantageous in developing monitoring methodologies and technologies. The IPCC Guidelines include provisions for reporting emissions from trans-boundary CCS projects and summarizes procedures for estimating and reporting emissions from $\mathrm{CO}_{2}$ storage sites, as shown in Figure 1.

\section{Conditions for Transboundary CCS-CDM}

\section{Condition 1}

$\mathrm{CO}_{2}$ is captured in Country A, transport and stored in Country B: as shown in Figure 2.

Country A should report the total amount of captured $\mathrm{CO}_{2}$, including: 1) any emissions from transport and/or temporary storage (that takes place in Country A), 2) the amount of $\mathrm{CO}_{2}$ stored in Country B.

Country $\mathrm{B}$ should report the total amount of $\mathrm{CO}_{2}$ imported, any emissions from transport and/or temporary storage (that takes place in Country B), and any emissions from injection in the geological storage sites.

\section{Condition 2}

$\mathrm{CO}_{2}$ is captured in Country A, transported thru Coun- try B and stored in Country C: as shown in Figure 3.

Country A should report: 1) the total amount of captured $\mathrm{CO}_{2} ; 2$ ) the total amount of $\mathrm{CO}_{2}$ transported thru Country $\mathrm{B} ; 3$ ) the total amount of $\mathrm{CO}_{2}$ stored in Country C.

\section{Condition 3}

$\mathrm{CO}_{2}$ is injected in Country A, but migrates and leaks in Country B: as shown in Figure 4.

If during the site characterization it is assumed a realistic probability of $\mathrm{CO}_{2}$ migration to a third country, Country B should sign an approval letter as a requirement from the Executive Board. If unexpected seepage or any secondary effect occurs, Country A should discuss with Country B to repair and to ensure long-term storage and monitoring.

\section{Condition 4}

More than one country utilizes a common storage site. as shown in Figure 5.

Countries A and B should report the amount of captured $\mathrm{CO}_{2}$ and any emissions from transport. The country where the geological storage takes place is responsible for reporting emissions from that site.

\section{Condition 5}

Storage site occurs in more than one third country. as shown in Figure 6.

Countries concerned should make an arrangement whereby each reports an agreed fraction of the total emissions.

\section{Analysis and Recommendation}

Much work is still to be done by the CCS community to ensure that the implementation of CCS under the CDM is both environmentally effective and commercially attractive. When considering CDM projects activities with a trans-boundary component, it is recommend that the rules of the main international treaties related to CCS be considered by the UNFCCC, especially the London Protocol guidelines for risk assessment and management and the 2006 IPCC Guidelines. Additionally, national governments should apply the rules and guidelines as delineated under the relevant existing international treaties and CCS national regulations.

After reviewing the main international and national regulations related to $\mathrm{CCS}$, some of the most important issues related to $\mathrm{CCS}$ under CDM with a trans-boundary component are discussed below:

- Endorsing guidelines for risk management developed under the main treaties to assure that trans-boundary CCS under CDM projects comply with international law obligations that address $\mathrm{CO}_{2}$ storage/seepage.

- Establishing criteria to assure that Trans-boundary CCS under CDM project activities are in compliance with relevant regulations on the national level.

- Following the rules and best practices of the main treaties, where applicable. 


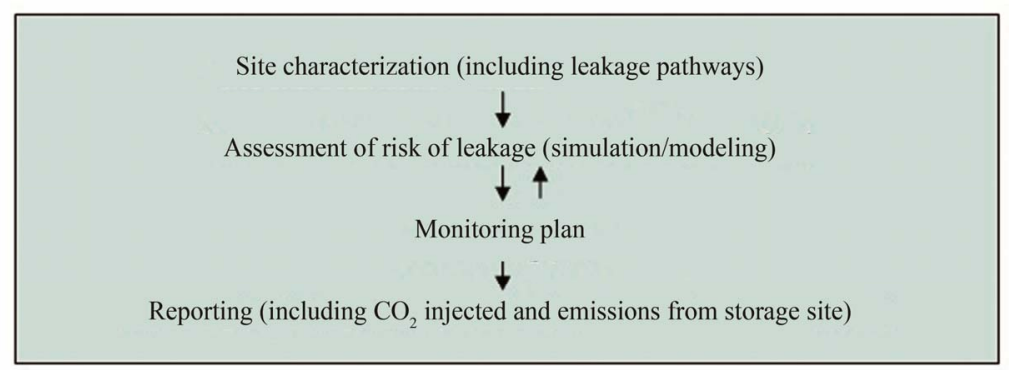

Figure 1. Methodology-estimating, verifying \& reporting emissions from $\mathrm{CO}_{2}$ storage sites; Source: IPCC, 2006.

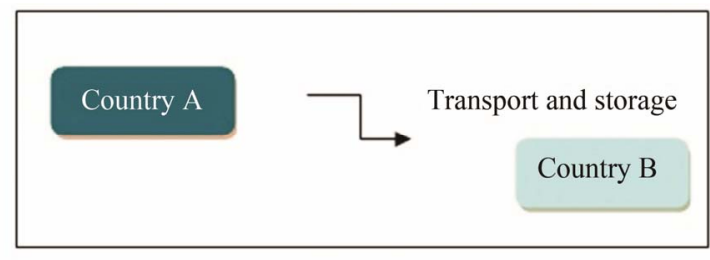

Figure 2. Condition 1.

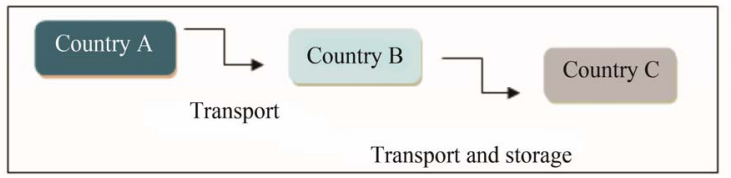

Figure 3. Condition 2.

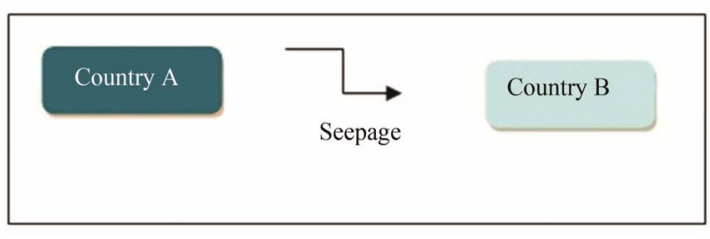

Figure 4. Condition 3.

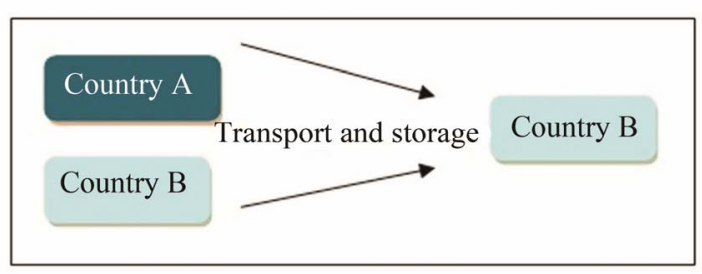

Figure 5. Condition 4.

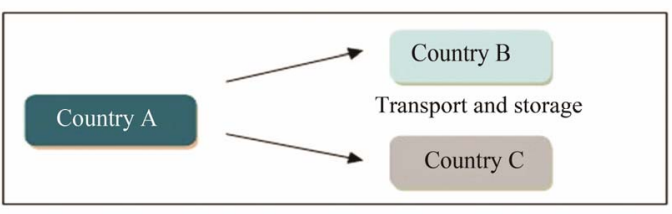

Figure 6. Condition 5.

\section{a) International and National Regulations}

- Ensuring that the issues are agreed with all parties and their national CCS regulations are consistent with related international requirements.

\section{b) Relevant Authority}

- Establishing criteria to register trans-boundary CCS under CDM project activities only where the Designated National Authorities (DNA) of all parties endorse national approval to host the project; If a second party does not have a DNA or relevant authority, the CCS under CDM project activities should be constrained to within national boundaries with no risk of migration.

- Establishing a competent authority for one jurisdiction to supervise the project or, conversely, establish a joint regulatory responsibility for operations.

\section{c) Liability}

- Requiring definition of long-term responsibility for the storage site and any associated liabilities, including measures to remediate the damages.

- Requiring definition of any transfer of liabilities between project participants and parties involved.

- The national approvals submitted by the DNAs should clearly specify the corresponding responsibilities of the host countries, including liability arrangements.

d) Seepage

- Following the rules and best practices of the main treaties, where applicable.

- Ensuring that project proponents have established appropriate arrangements to address any trans-boundary seepages.

- Ensuring environmental regulatory frameworks that provide in both countries.

\section{e) Boundary}

- Ensuring a clear definition of the extent of the project boundary to guarantee that migration of $\mathrm{CO}_{2}$ to other underground sites is detected. This definition includes the extent of the reservoir and others reservoirs above the aimed storage reservoir.

- Disqualifing CDM registration where trans-boundary issues are not completely resolved to the satisfaction of all the joint countries.

- Ensuring that no issue related to a trans-boundary component is in conflict in both countries. 


\section{Conclusions}

The previous mentioned points are some of the key issues that need to be addressed in order to include transboundary CCS under CDM projects. Because these concerns are about deployment of multiple large injection systems, they should not present an impediment to nearterm development of commercial storage projects. Project developers should anticipate future investigations into the potential effects of multiple project deployments.

The analysis suggests more centralized regulation of storage projects. Regulators should consider how to most efficiently address this concern in order to reduce the chance of unintended consequences. The analysis and the debate about the methodologies submitted for real cases may be helpful to elucidate other questions, to enhance the safety and to assure a sustainable inclusion of CCS under CDM.

There are currently many international, regional and local legal frameworks somewhat relevant to CCS activities and many definitions and prohibitions within these frameworks could be adequately broad to encompass and regulate various $\mathrm{CO}_{2}$ capture and geological storage activities. Other current CCS guidelines and regulatory frameworks could also support countries to effectively implement cross-border projects, and a very robust CDM procedure and rules for trans-boundary projects should be carefully structured.

\section{Acknowledgements}

The authors would like to express their acknowledge to Sarah Forbes and Francisco Almendra, from the World Resources Institute (WRI), James Jim Dooley, from the Joint Global Change Research Institute (JGCRI) and Nathan Hultman, from the University of Maryland (UMD), for their precious help and contribution on discussions about the topic of this paper. Additionally, the authors would like to thank the support of the Research Center of Carbon Emission Policy and Regulation (NUPPREC), from the University of Sao Paulo (USP), Brazil.

\section{REFERENCES}

[1] UNFCCC, "Modalities and Procedures for Carbon Dioxide Capture and Storage in Geological Formations as Clean Development Mechanism Project Activities," 2011. http://unfccc.int/files/meetings/durban_nov_2011/decisio ns/application/pdf/cmp7carbonstorage.pdf

[2] UNFCCC, "Technical Workshop on Modalities and Procedures for Carbon Dioxide Capture and Storage in Geological Formations as Clean Development Mechanism Project Activities," 2011.

http://unfecc.int/methods_and_science/other_methodologi cal_issues/items/6144.php

[3] UNFCCC, "Views Related to Carbon Dioxide Capture and Storage in Geological Formations as a Possible Mitigation Technology. Subsidiary Body for Scientific and Technological Advice (SBSTA 32)," 2010. unfccc.int/resource/docs/2010/sbsta/eng/misc02.pdf

[4] UNFCCC, "Modalities and Procedures for CCS in Geological Formations as Clean Development Mechanism Project Activities," 2011. http://unfccc.int/resource/docs/2011/sbsta/eng/inf07.pdf

[5] "London Convention on the Prevention of Marine Pollution by Dumping of Wastes and Other Matter," 1972. http://www.londonconvention.org/documents/lc72/LC197 2.pdf

[6] IMO, "London Convention and Protocol," 2012. http://www.imo.org/OurWork/Environment/SpecialProgra mmesAndInitiatives/Pages/London-Convention-and-Protocol.aspx

[7] R. Macrory, et al., "UCL Carbon Capture Legal Programme CCS in the Clean Development Mechanism," 2011. http://www.ucl.ac.uk/cclp/ccsinCDM.php

[8] "Basel Convention on the Control of Trans-Boundary Movements of Hazardous Wastes and their Disposal," 1989. http://archive.basel.int/ratif/convention.htm

[9] IPCC-Intergovernmental Panel on Climate Change, "Carbon Dioxide Capture and Storage," Special Report, In: B. Metz, O. Davidson, H. de Coninck, M. Loos and L. Meyer, Eds., Cambridge University Press, Cambridge, 2005.

[10] "ESPOO Convention on Environmental Impact Assessment in Transboundary Context," 1991.

http://www.unece.org/fileadmin/DAM/env/eia/documents /legaltexts/conventiontextenglish.pdf

[11] "London Protocol Adopts Amendment Allowing for Subseabed Carbon Dioxide Storage." http://pdf.wri.org/css_06_12_08_london_protocol.pdf

[12] OSPAR, Commission Secretariat, 1992. http://www.ospar.org/welcome.asp?menu $=0$

[13] WRI, "Carbon Dioxide Capture and Storage and the UNFCCC: Recommendations for Addressing Technical Issues," 2011.

http://www.wri.org/publication/carbon-dioxide-capture-a nd-storage-and-the-UNFCCC.

[14] IMO - International Maritime Organization, "Information on Work on CCS in Sub-Seabed Geological Formation and Ocean Fertilization under the London Convention and London Protocol," 2010.

http://www.imo.org/OurWork/Environment/PollutionPreven tion/AirPollution/Documents/COP\%2016\%20Submissions/I MO\%20note\%20on\%20LC-LP\%20matters.pdf

[15] International Energy Agency, "CCS Regulatory Model Framework," IEA, Paris, 2010. http://www.iea.org/ccs/legal/model_framework.pdf

[16] IEA, "Legal Aspects of Storing $\mathrm{CO}_{2}$ : Update and Recommendations," IEA, Paris, 2010. 